\title{
Enseñanza de operaciones matemáticas con scratch: notas para el aprendizaje construccionista mediado por tecnologías digitales
}

\author{
Marcelo Miranda Damasceno ${ }^{1}$ \\ marcelo.damasceno@ifpa.edu.br \\ https://orcid.org/0000-0001-8748-7728 \\ Sebastião Rodrigues-Moura ${ }^{1}$ \\ sebastiao.moura@ifpa.edu.br \\ https://orcid.org/0000-0003-4254-6960 \\ ${ }^{1}$ Instituto Federal de Educação, Ciência e Tecnologia do Pará (IFPA, Brasil)
}

Recibido: 07/05/2020 Aceptado: 06/07/2020

\begin{abstract}
Resumen
En esta investigación, analizamos los elementos de la práctica pedagógica mediada por las tecnologías digitales para un aprendizaje construccionista de las operaciones matemáticas. Para lograr este objetivo, nos hemos apropiado del enfoque cualitativo de la investigación, organizado a la luz de una intervención pedagógica para explorar, a través del lenguaje de programación, las operaciones básicas de números enteros, un juego matemático y un robot que sigue una línea virtual. La experiencia se registró en un diario de enseñanza, que sirvió como material empírico para la recopilación y el análisis de los datos. Dos dimensiones formativas surgieron del análisis de estos registros: la reflexión sobre la práctica pedagógica y las lecturas educativas. Los resultados revelaron un proceso interactivo y dinámico de conocimiento matemático a través de tecnologías digitales, integrado con el contexto social del aula, concibiendo el desarrollo del razonamiento lógico, la creatividad y la capacidad de trabajar en equipo. Estas características infieren sobre el potencial de la planificación pedagógica desvelada en la práctica de contenidos específicos y pedagógicos para mediación de la transformación del conocimiento matemático.
\end{abstract}

Palabras clave: Educación matemática; Scratch; Tecnologías digitales.

\section{Ensino de operações matemáticas com scratch: apontamentos para uma aprendizagem construcionista mediada por tecnologias digitais}

\section{Resumo}

Nesta pesquisa, analisamos os elementos da prática pedagógica mediada por tecnologias digitais para uma aprendizagem construcionista de operações matemáticas. Para atingir este objetivo, apropriamo-nos da abordagem qualitativa da pesquisa, organizada à luz de uma intervenção pedagógica para explorar, por meio da linguagem de programação, as operações básicas de números inteiros, um jogo matemático e um robô seguidor de linha virtual. A experiência foi registrada em um diário de docência, que serviu como material empírico para a coleta e análise dos dados. Da análise desses registros emergiram duas dimensões formativas: a reflexão sobre a prática pedagógica e os apontamentos didáticos. Os resultados revelaram um processo interativo e dinâmico do conhecimento matemático por meio de tecnologias digitais, integrado ao contexto social de sala de aula, vislumbrando o desenvolvimento do raciocínio lógico, da criatividade e da habilidade em trabalhar em equipe. Tais características inferem sobre o potencial do planejamento pedagógico desvelado 
na prática dos conteúdos específicos e pedagógicos para a mediar a transformação dos saberes matemáticos.

Palavras-chave: Educação em Matemática; Scratch; Tecnologias digitais.

\title{
Teaching mathematics operations with scratch: notes for constructionist learning mediated by digital technologies
}

\begin{abstract}
In this research, we analyze the elements of pedagogical practice mediated by digital technologies for a constructionist learning of mathematical operations. To achieve this goal, we appropriated the qualitative approach of research, organized in the light of a pedagogical intervention to explore, through the programming language, the basic operations of whole numbers, a mathematical game and a robot that follows a virtual line. The experience was recorded in a teaching diary, which served as empirical material for data collection and analysis. Two formative dimensions emerged from the analysis of these records: the reflection on the pedagogical practice and the educational readings. The results revealed an interactive and dynamic process of mathematical knowledge through digital technologies, integrated with the social context of the classroom, envisioning the development of logical reasoning, creativity and the ability to work as a team. These characteristics infer about the potential of pedagogical planning unveiled in the practice of specific and pedagogical contents to mediate the transformation of mathematical knowledge.
\end{abstract}

Keywords: Mathematics Education; Scratch; Digital technologies. Constructionism.

\section{Introdução}

As tecnologias digitais oriundas do mundo globalizado têm modificado de sobremaneira o modo de vida e as formas de se relacionar em sociedade. Este novo modo de relacionamento tem transformando a forma de viver, de pensar e agir das pessoas, empresas e, sobretudo, teve efeito imediato na educação. O processo educativo passou por grandes mudanças ao longo dos séculos e, graças ao nosso acentuado desenvolvimento tecnológico e científico das últimas décadas, fez com que o modelo tradicional de "transmissão de conhecimento" entre professor e aluno se tornasse defasado e, com urgente necessidade, tem apresentado reinvenções na forma de ensinar e aprender.

Essas transformações trouxeram novos elementos tecnológicos para dentro do ambiente escolar, isto porque tecnologias digitais como smartphones, notebooks, televisores inteligentes, mídias digitais e outros canais de informação e comunicação incorporados à internet por meio das redes sociais, já são de domínio da maioria dos jovens - os chamados nativos digitais. Nesse tocante, a escola parece ter "ficado para trás", "desatualizada", "pouco atrativa" e, mesmo quando equipada, seu uso ainda se dá como uma mera 
substituição do antigo quadro negro pelo digital, perpetuando-se o modelo de ensino tradicional, pautada na transmissão de conhecimento do professor ao aluno, da racionalidade técnica.

Ao longo dos últimos anos, debates como estes, estão se tornando mais frequentes nos meios acadêmicos por diferentes autores, tais como Sampaio e Leite (1999), Santos (2012), Carneiro e Passos (2014), Cabral (2015), Baião (2016), Hernandez (2017), RiveraVargas e Lindín (2018) e Almeida et al. (2019). À primeira vista, pode parecer que o problema esteja somente na falta de capacitação do professor, contudo, deve-se atentar para o fato de que o sistema público de ensino é um ecossistema fechado, com grade curricular apertada, que cobra resultados concretos, com avaliação mensurada por notas, em muitos casos sem infraestrutura e com carga horária extenuante, o que pode dificultar ao docente inovar no cotidiano escolar, na sua metodologia de ensino. Ainda assim, salientamos que o professor permite a superação e busca apropriar-se desses novos meios tecnológicos, visando dinamizar o ensino e a aprendizagem de seus alunos, de forma eficaz.

Percebemos que o problema passa a assumir uma dimensão maior - um caso de gestão pedagógica. Essa barreira pode ser parcialmente superada com a adoção de algumas medidas, dentre elas a flexibilização de conteúdos e, atribuindo de fato, tempo e liberdade para que o docente possa se apropriar e aplicar dinâmicas de ensino-aprendizagem apoiadas em tecnologias digitais, contribuindo-se para que haja uma mudança das práticas pedagógicas, pois não dá para obter sucesso diante desta nova demanda, sem fazer um definitivo rompimento com as velhas práticas educativas.

A motivação para a proposição desta pesquisa de intervenção pedagógica, surgiu devido à nossa inquietude no que concerne ao rendimento auferido pelos alunos do Ensino Fundamental em relação aos conteúdos básicos da disciplina de Matemática. Do exposto, procuramos desenvolver uma intervenção para um conteúdo específico matemático, a citar as “Operações com Números Inteiros”, buscando aprofundar a sua compreensão, utilizando a informática e a limguagem de programação com o uso do Scratch como uma tecnologia digital, para oferecer ao aluno uma instrumentalização que faça uso próprio para o seu diaa-dia e ao desenvolvimento/aprimoramento das nossas práticas educacionais.

Estas funcionalidades tornaram-se ideais para explorar junto aos alunos importantes conceitos matemáticos com as operações envolvendo números inteiros, utilizando-se algoritmos de programação próprios da programação, com vistas a desenvolver seu 
raciocínio lógico, cognitivo e o pensamento computacional sob a ótica da proposta construtivista de Papert (1994). A proposta emerge como uma alternativa para a aprendizagem dos discentes, fazendo uso de tecnologias digitais, linguagem de programação e jogos midiáticos para despertar o interesse diante das concepções matemáticas.

Tais questionamentos e perspectivas balizaram o desenvolvimento e a aplicação prática desta proposta de intervenção pedagógica, direcionada à aprendizagem matemática de alunos de uma turma do $7^{\circ}$ ano do Ensino Fundamental, em uma escola pública do município de Marabá, sudeste do estado do Pará, Brasil. Após um diagóstico sobre o aproveitamento das turmas na escola, optamos pela turma citada devido ao seu alto índice de reprovação, principalmente relacionado aos conteúdos de Matemática; desta forma, propomos uma maneira de abordagem pedagógica utilizando a programação com Scratch.

Sanches (2004) e Bicudo e Borba (2005) argumentam que a Matemática é considerada por muitos alunos como uma ciência abstrata e de difícil compressão, o que dificulta a aprendizagem, mas todos reconhecem que a sua importância para entender o mundo em que se vive. Além da abstração natural da disciplina, seu ensino ainda é ministrado com pouco vínculo do contexto social, tornando seu conteúdo muitas vezes sem sentido. O processo de aprendizagem matemática não é uma tarefa trivial, pois não depende somente dos esforços dos professores, assim como a aprendizagem não é algo que depende somente dos alunos, uma vez que ambos se explicam mutuamente (Freire, 1996). O modelo de ensino tradicional, estático, adestrador, aliados à excessiva carga horária, aos baixos salários, à falta de interesse dos alunos e à falta de apoio dos familiares dos educandos, são fatores que não oferecem um terreno fértil para o seu desenvolvimento, devendo ser atrelada à formação específica e pedagógica, visando romper com o modelo da racionalidade técnica (Nóvoa, 1992; Fiorentini, 2008).

Desse modo, verifica-se a necessidade de uma mobilização mais ampla para o fortalecimento da prática pedagógica, incluindo a participação da sociedade, dos gestores escolares e, principalmente, de investimentos e fomento a projetos educacionais concretos, com resultados visíveis a médio e longo prazo, dando frutos à aprendizagem matemática, por meio do raciocínio, da compreensão, do espírito crítico e não-repetitivo (Kamii, 1995). Neste enfoque, ao usarmos o Scratch buscamos oportunizar aos estudantes a incorporação do raciocínio lógico-dedutivo de uma maneira tecnologicamente inovadora, a fim de estimular a sua criatividade por meio do uso de tecnologias digitais, assim como contribuir para a apreensão do conhecimento de forma mais natural, duradoura e divertida; fatores 
importantes para o seu desenvolvimento social e intelectual, entrelaçados com os saberes matemáticos.

Assim sendo, ocupamo-nos na presente pesquisa em analisar os elementos da prática pedagógica mediada por tecnologias digitais para uma aprendizagem construcionista de operações matemáticas. Por se tratar de um objetivo mais amplo, desvelamos especificamente em (i) identificar elementos de ensino e da aprendizagem para a apropriação do conhecimento matemático diante de uma proposta construcionista; e, (ii) desenvolver o compartilhamento e a interação social escolar, com propósito de partilhar experiências, visando o surgimento de ideias que possam aperfeiçoar o processo de ensino-aprendizagem.

\section{Percursos metodológicos da pesquisa}

Nesta pesquisa, desenvolvemos por meio de uma intervenção pedagógica o apoio ao ensino e à aprendizagem da Matemática através da inclusão de tecnologias digitais, para que pudesse ocorrer como uma construção mútua e interativa. Essa vinculação contínua reflete com a questão central desta pesquisa pelo fato de criar reflexões do professor sobre a sua prática a partir da interação aluno-tecnologia digital, norteando todo o processo de investigação para a compreensão de novas relações e da realidade experienciada (Soares, 2005).

Neste sentido, buscamos explorar conceitos de operações matemáticas com números inteiros, através de algoritmos de programação gráfica e intuitiva com foco na linguagem de programação (Zilli, 2004), utilizando como ferramenta o aplicativo Scratch, sob a ótica da teoria construcionista de Papert (1994). O fato de usarmos a programação para a aprendizagem matemática se justifica para o enfrentamento de desafios escolares na constituição da linguagem dos alunos, produção de histórias interativas, jogos e animações a serem compartilhadas com outras pessoas, primando-se pela capacidade de aprimorar habilidades e lidar com tecnologias digitais (Papert, 1994; Jenkins et al., 2009, Sápiras et al., 2015).

A linguagem de programação Scratch foi criada com base na linguagem Logo® desenvolvida pelo laboratório do MIT (Massachusetts Institute of Technology), cujo objetivo era instigar as crianças a programar robôs ou representações deste, na tela do computador. 
Cabe frisar que o Scratch é um projeto do grupo Lifelong Kindergarten no Media Lab do MIT, onde foi idealizado por Mitchel Resnick ${ }^{1}$.

Segundo Castro \& Koscianski (2017), o projeto Scratch teve início em 2013 e, a partir de 2007, seu site foi lançado na internet, como um software gratuito e disponível tanto on-line como off-line pata aprendizagem criativa e colaborativa. Santos (2017) aponta que a ferramenta Scratch foi concebida segundo a perspectiva Construcionista e propõe que o aprendiz interaja com a máquina de forma a "ensiná-la" na execução uma ação, resolver um problema ou cumprir uma rotina. Assim, o aluno poderá elaborar seu próprio projeto sozinho ou em grupo, trabalhando de forma colaborativa em torno de um mesmo computador, compartilhando seu projeto e experiências no site da ferramenta; fatores que o torna ideal para o propósito deste projeto de intervenção utilizando a programação.

O diferencial desta ferramenta está na forma como a programação é realizada, pois aquelas linhas de códigos difíceis de programar e decifrar estão embutidas por trás da interface do aplicativo. Na linguagem de programação Scratch as crianças aprendem a programar brincando, simplesmente encaixando os blocos lógicos uns nos outros como se fossem um quebra-cabeça, o que torna o aprendizado mais fácil e divertido, além de possibilitar aos usuários desenvolver diversas competências como raciocínio lógico, pensamento sistêmico e resolução de problemas (Castro \& Koscianski, 2017).

Outra vantagem que a ferramenta oferece é a possibilidade de compartilhamento dos projetos desenvolvidos no $\operatorname{site}^{2}$, de forma pública, onde também é possível encontrar milhares de outros projetos que podem ser melhorados continuamente por qualquer participante, que também podem servir de base para outros projetos.

A partir desta contextualização da intervenção pedagógica e como pesquisadores qualitativos, pautamos nossas análises e discussões na abordagem qualitativa de pesquisa como meio de compreender e se familiarizar com os pressupostos da investigação, além de tecer aproximações com o objeto de estudo, de modo a argumentar a partir de experiências vivenciadas e dos aportes teóricos que fomentam os resultados da intervenção (Minayo, 2012). Além disso, nos apropriamos da pesquisa bibliográfica, quanto aos procedimentos iniciais de pesquisa, para os quais recorremos à literatura que aborda a inclusão de

\footnotetext{
${ }^{1}$ Resnick é bacharel em física pela Universidade de Princeton (1978) e mestrado e doutorado em ciência da computação pelo MIT (1988, 1992). Trabalhou como jornalista de ciência e tecnologia de 1978 a 1983. Ele recebeu o PrêmioMcGraw em Educação em 2011 e o Prêmio AACE EdMedia Pioneer em 2013. Disponível em: https://www.media.mit.edu/people/mres/overview/. Acesso: 14 jun. 2018.

${ }^{2}$ Os projetos podem ser acessados gratuitamente na plataforma. Maiores informações: https://scratch.mit.edu/
} 
tecnologias digitais para o ensino/aprendizagem da Matemática. E, de posse dessas informações, traçamos os objetivos e as estratégias necessárias para a aplicação prática da intervenção, a um número específico de alunos, abordando um tema à primeira vista, limitado, para o Ensino Fundamental.

Em um segundo plano, articulados aos dados iniciais, demos atenção à organização e ao planejamento didático/metodológico, organizado em cinco encontros a serem realizados sempre às terças-feiras, nos quais construímos um plano de aula específico para cada encontro. O plano de aula seguinte era dependente dos resultados positivos ou negativos obtidos no encontro anterior, anotados e registrados no diário de docência (RodriguesMoura, 2016) do professor-aplicador, o que pode facilitar o nosso trabalho, além de clarear os possíveis objetivos (e metas) para ampliar e melhorar continuamente as práticas pedagógicas estabelecidas.

Os diários de docência serviram como documento norteador contendo excertos dos registros, anotações e observações feitas por nós, com o intuito de coletar duas importantes dimensões formativas: a primeira voltada para tecer reflexos e reflexões sobre como se deu a prática de sala de aula, em função da ação do professor na mediação pedagógica; já a segunda na busca por discorrer de características que desvelaram a intervenção realizada com o intuito de compreender o encontro atual e prospectar-se sobre os próximos encontros, balizando assertivas que melhor atendessem a aprendizagem matemática.

Dessa forma, os diários serviram com instrumento de coleta de dados, analisados à luz do que víamos, ouvíamos e vivenciamos na sala de aula, como forma de esboçar o cenário da pesquisa, a compreensão sobre a realidade e a práxis pedagógica. Os fragmentos do diário foram analisados qualitativamente sob o nosso olhar de pesquisadores em educação, de modo a permitir uma melhor contextualização dos encontros, situando-os em duas dimensões formativas: a Reflexão sobre a Prática Pedagógica e os Apontamentos Didáticos. Sobre essas dimensões, nos inspiramos em Bogdan e Biklen (1994) para situar a prática em forma de aspectos descritivos, dos quais os textos de campo emergem como textos de pesquisa, escritos de forma argumentativa e implícita à experiência desenvolvida.

\section{Sequência de Análise: discutindo os resultados}

As aulas foram planejadas por meio de minirroteiros elaborados em parceria com o professor da disciplina, cujo objetivo era desenvolver animações que representassem o 
resultado de operações com números inteiros, através da linguagem de programação Scratch, aplicadas aos alunos como aula de nivelamento de aprendizagem. Cada aula continha dois objetivos, um explícito e o outro implícito: o primeiro com vista a averiguar se os alunos conseguiam aplicar na programação, algoritmos envolvendo conceitos de operações com números inteiros e o segundo servia para avaliar o aprendizado de conceitos de conteúdos futuros e indispensáveis para a programação básica de um robô seguidor de linha virtual.

No primeiro encontro foi apresentada a interface do programa Scratch aos alunos e foi-lhes solicitado que criassem seus primeiros programas, com o intuito de criar um ambiente descontraído e favorável à interação social entre todos os participantes, estabelecendo expectativas para os próximos encontros. As atividades foram pensadas para serem realizadas em duplas, pois almeja o desenvolvimento de habilidades em trabalhos de equipe, relacionamento interpessoal e administração de conflitos, que são qualidades indispensáveis para se viver em uma sociedade diversificada, inclusive no ambiente plural da sala de aula.

Depois que todos tiveram domínio básico do software, demos início às abordagens matemáticas. Os programas criados foram compartilhados no site oficial ${ }^{3}$ do Scratch, onde todos os participantes e a comunidade poderão baixar, reescrever e melhorar continuamente de acordo com seu contexto, favorecendo a aprendizagem autônoma.

As atividades da intervenção pedagógica foram aplicadas para uma turma de $7^{\circ}$ ano do Ensino Fundamental, com um encontro semanal de 90 minutos cada, entre os períodos de 08 de maio a 12 de junho de 2018, sempre nos horários cedidos pelo professor de Matemática. Foram realizados cinco encontros com a turma e as atividades propostas foram organizadas com planos de aulas desenvolvidos para cada encontro, contendo objetivo geral e específicos, conteúdos a ministrar e formas de avaliação, sendo todas as observações do andamento da intervenção registradas no diário de docência. As atividades de programação foram planejadas para serem trabalhadas por duplas de alunos, com o objetivo de desenvolver as habilidades de trabalho em equipe, cooperação e resolução de problemas.

\section{Primeiro Encontro: Introdução à Programação com Scratch}

Iniciamos este encontro com uma apresentação expositiva sobre o projeto de intervenção com o auxílio de um projetor multimídia e um notebook, cedidos pela escola.

\footnotetext{
${ }^{3}$ Idem.
} 
Estiveram presentes no primeiro encontro 21 alunos, acompanhados pelos professores de Matemática e Informática da escola.

Em seguida, o professor-pesquisador (autor principal desta pesquisa) pediu para que os alunos se organizassem em duplas, ligassem seus computadores na tentativa de otimizar o tempo e, a seguir, virassem suas cadeiras de frente para o projetor de modo a assistir a um vídeo institucional sobre o Scratch. Esclarecemos sobre a necessidade do planejamento prévio acerca do que se pretende programar, haja vista que os blocos de programação devem ser encaixados de forma sequencial para que os resultados da animação façam sentidos.

Como forma de mediação pedagógica, orientamos aos alunos que este tipo de programação está voltado para que as instruções sejam dadas ao computador e este, por sua vez, execute os comandos estabelecidos: este conceito inicial é a base da proposta construcionista que orienta esta pesquisa. Desta forma, pedimos que dessem especial atenção à paleta de códigos, pois cada grupo é diferenciado pelas cores e independente dentre eles, sendo assim, deveriam estar bem claras as instruções necessárias para a programação de cada tarefa.

Após a apresentação inicial, solicitamos que os alunos reorganizassem suas cadeiras e aguardassem por novas instruções para dar início a uma exploração guiada pela interface do aplicativo. Em seguida, com o auxílio do projetor, começamos a fazer uma explanação mais detalhada sobre cada uma das partes que compõem o aplicativo, conforme Figura 1.

Figura 1: Detalhes da interface do Scratch

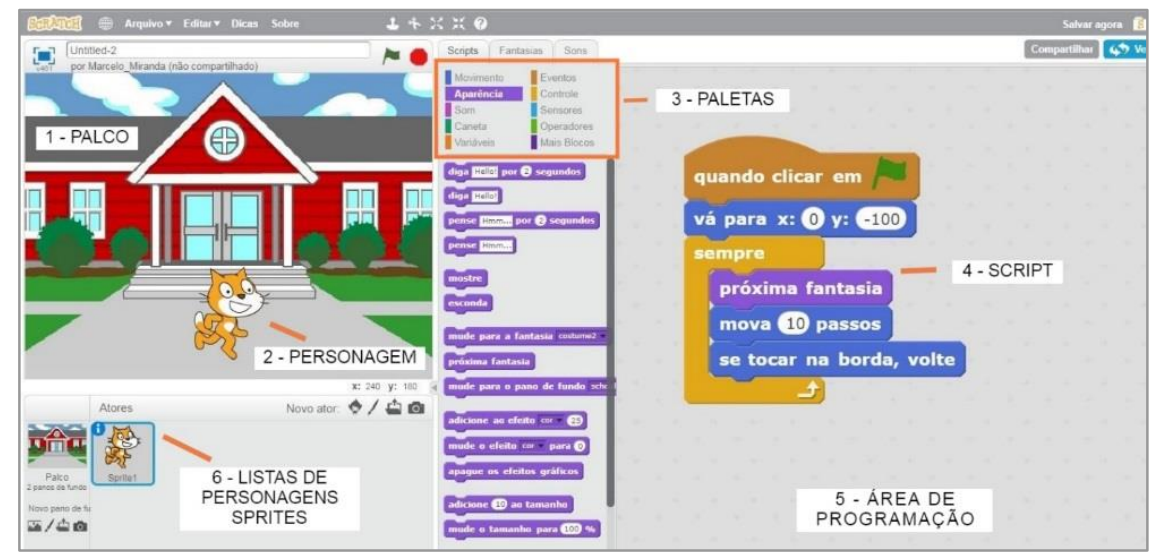

Fonte: Elaborada pelos autores (2018)

Após estes procedimentos, as duplas foram orientadas a criar a primeira animação simples, utilizando blocos de programação sugeridos, mas os personagens (sprites) deveriam ser escolhidos conforme sua criatividade, como vistos na Figura 2. 
Figura 2: Animação do personagem (sprite) na horizontal e o script que o executa

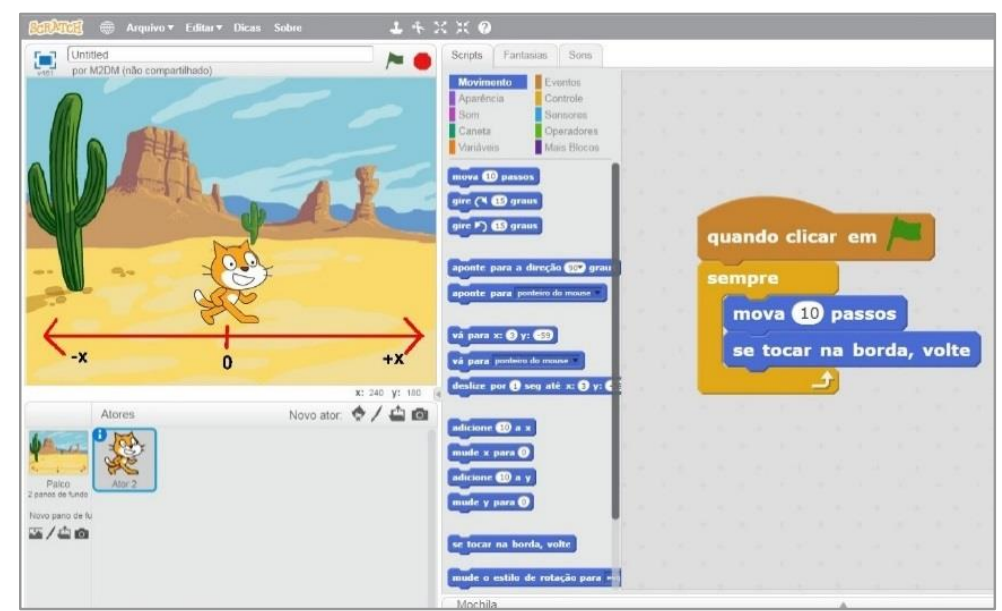

Fonte: Elaborada pelos autores (2018)

O programa sugerido faz com que o sprite (gatinho) se locomova na horizontal até que bata na borda da tela, condição no qual o gato mudará de direção. Para que a animação ocorra conforme o desejado, é necessário que um grupo de instruções seja executado de forma sequencial, iniciando por um bloco de controle que está aguardando por uma decisão do usuário (ao clicar na bandeira verde), depois disso o bloco de decisão sempre faz com que as instruções que estão em seu interior sejam executadas continuamente e o bloco mova 10 passos (somam 10 passos em relação à posição anterior de $x$ ), fazendo com que o gato ande até bater na borda, quando deverá voltar.

Depois, solicitamos que modificassem o código inserindo outros blocos ainda não ensinados (Figura 3) com o objetivo de gerar novas descobertas, gerando neles satisfação, engajamento e ansiedade para nosso próximo encontro, como propõe a abordagem construcionista de Papert (1994). Depois das modificações, percebemos resultados positivos nas animações como movimentos na vertical, na diagonal, aleatórios, com velocidades diferenciadas e com mais de um personagem ao mesmo tempo, conforme registramos no diário de docência, o que nos assegura um estímulo à mediação da aprendizagem.

Figura 3: Alterações do script e personagem realizado por um aluno

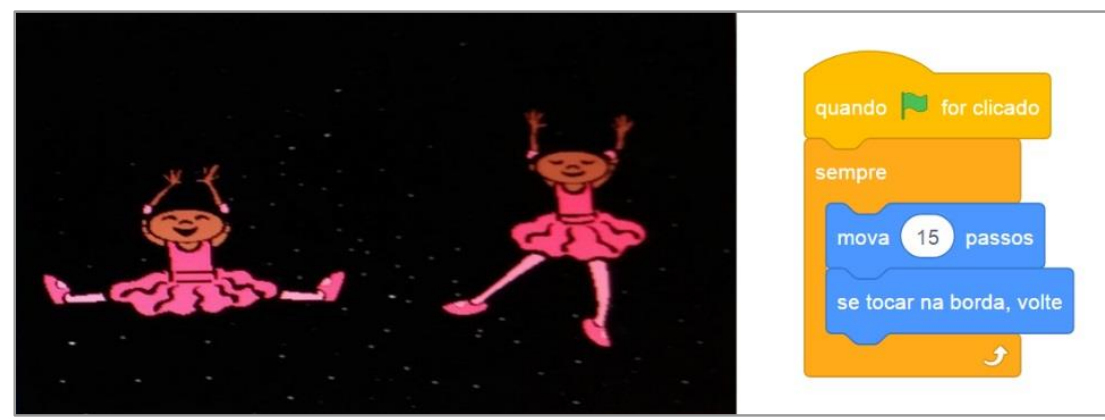

Fonte: Elaborada pelos autores (2018) 
O objetivo por trás da criação deste programa básico está para além da abordagem dos comandos do Scratch, pois as animações gráficas na tela do aplicativo são realizadas através da variação dos valores dos pares ordenados $(x, y)$ no plano cartesiano. Dessa forma, exploramos os conceitos sobre números positivos e negativos, números simétricos e a importância de seu aprendizado para a programação de jogos, robôs, leituras de gráficos, mapas cartográficos, entre outros. Percebemos também que os alunos expressaram surpresa com o tipo de abordagem matemática realizada através da programação, o que reforça a potencialidade da inserção de tecnologias digitais no ensino da aprendizagem matemática.

Apesar do êxito do primeiro encontro, foram verificados dois problemas que persistiram durante todo o período de aplicação da intervenção: um relacionado à climatização gerada pelos condicionadores de ar antigo e mal dimensionados e o outro, devido à má qualidade das imagens geradas pelo datashow, que exibia imagens apagadas e sem brilho, dificultando a visualização do conteúdo apresentado, o que gerou certa desatenção em muitos alunos.

\section{$\underline{\text { Reflexões sobre a Prática Pedagógica }}$}

Em linhas gerais, a quantidade de computadores foi suficiente para suprir o quantitativo de alunos, contudo registramos reclamações de alguns alunos que alegavam que o script criado apagava ou sumia da tela. Após breve análise, verificamos que parte do problema era devido a falhas no mouse ou teclado e a outra parte era resultado da interferência de outros alunos que desligavam ou apagavam o programa do colega. Outra dificuldade encontrada foi quanto ao layout dos computadores posicionados de costa para o professor que foram fatores relevantes ao controle e ao acompanhamento das aulas expositivas, pois os alunos tinham que virar as cadeiras para poder visualizar o que era exibido pelo projetor multimídia. No entanto, parte desses problemas puderam ser melhor administrados com o auxílio dos professores de Matemática e Informática que participaram dos encontros iniciais e já conheciam as características comportamentais da maioria dos alunos.

\section{$\underline{\text { Apontamentos Didáticos }}$}

Apesar do alvoroço inicial, percebemos que houve envolvimento e interação entre eles, pois alguns alunos aprenderam rápido e passaram a auxiliar os colegas que estavam com alguma dificuldade, o que veio a demonstrar habilidades no manuseio de recursos 
tecnológicos. Outro fator importante observado refere-se à situação que muitos alunos conseguiram aplicar ou reconhecer o "jogo de sinais", a localização de números positivos e negativos na reta numérica, explorados através da movimentação horizontal do personagem na tela do Scratch, o que demonstra que já possuíam conhecimento matemático prévio. Portanto, o programa realmente chamou a atenção dos participantes e parte deste crédito está relacionado ao fato de o aplicativo ter uma interface intuitiva, contribuindo para que os alunos explorassem com maior curiosidade o programa, inclusive fazendo uso de recursos avançados ainda não ensinados, como por exemplo colocar sua própria foto no fundo do palco usando a webcam, mudar a cor do personagem e colocar sons na animação. Quanto à interação entre os participantes, avaliamos como favorável, pois em momentos de dúvidas ou dificuldades, os mesmos procuraram suporte junto a outras equipes, além da satisfação em poder compartilhar suas descobertas com seus colegas espontaneamente.

\section{Segundo Encontro: Introdução às operações com números inteiros na reta numérica}

Para o segundo encontro, fizemos duas melhorias estratégicas no modo de apresentação para tentar mitigar as dificuldades verificadas no encontro anterior. $\mathrm{Na}$ aula anterior, pedimos que cada dupla ligasse previamente o seu computador, o que acabou ocasionado desatenção no momento da explicação introdutória, devido ao fato de muitos começarem a jogar e ao layout das bancadas ficarem de costas para o professor. Para contornar a situasão, pedimos que os alunos não ligassem os computadores até que acabasse a explicação, assim todos puderam compreender melhor os objetivos da aula e o que era esperado deles. Para resolver parcialmente os problemas com a qualidade da imagem do projetor, inserimos minirroteiros impressos que foram entregues a cada equipe com instruções básicas acerca da tarefa a ser realizada, com isso conseguimos otimizar o tempo e os alunos tornaram-se mais independentes. Obtivemos êxito com este tipo de abordagem e a constituímos como a base aos próximos encontros.

O objetivo deste encontro foi o de desenvolver um algoritmo que desenhasse na tela um polígono regular (Figura 4). Enfatizamos a importância do aprendizado das operações com números inteiros positivos/negativos e a necessidade em dominá-las para poder posicionar um objeto em um ponto qualquer do plano cartesiano, além da sua relevância para o aprendizado de conteúdos futuros como análises gráficas, cartográficas e mapeamentos diversos incluindo os utilizados pelo Google Maps, GPS de celulares, dentre outros. 
Exploramos nesse encontro, novos blocos lógicos como a caneta, o controle e a importância do planejamento sequencial da rotina responsável por fazer o desenho na tela, procurando desenvolver nos alunos a habilidade de análise, raciocínio lógico, abstração e pensamento computacional.

Figura 4: Desenho de um polígono regular

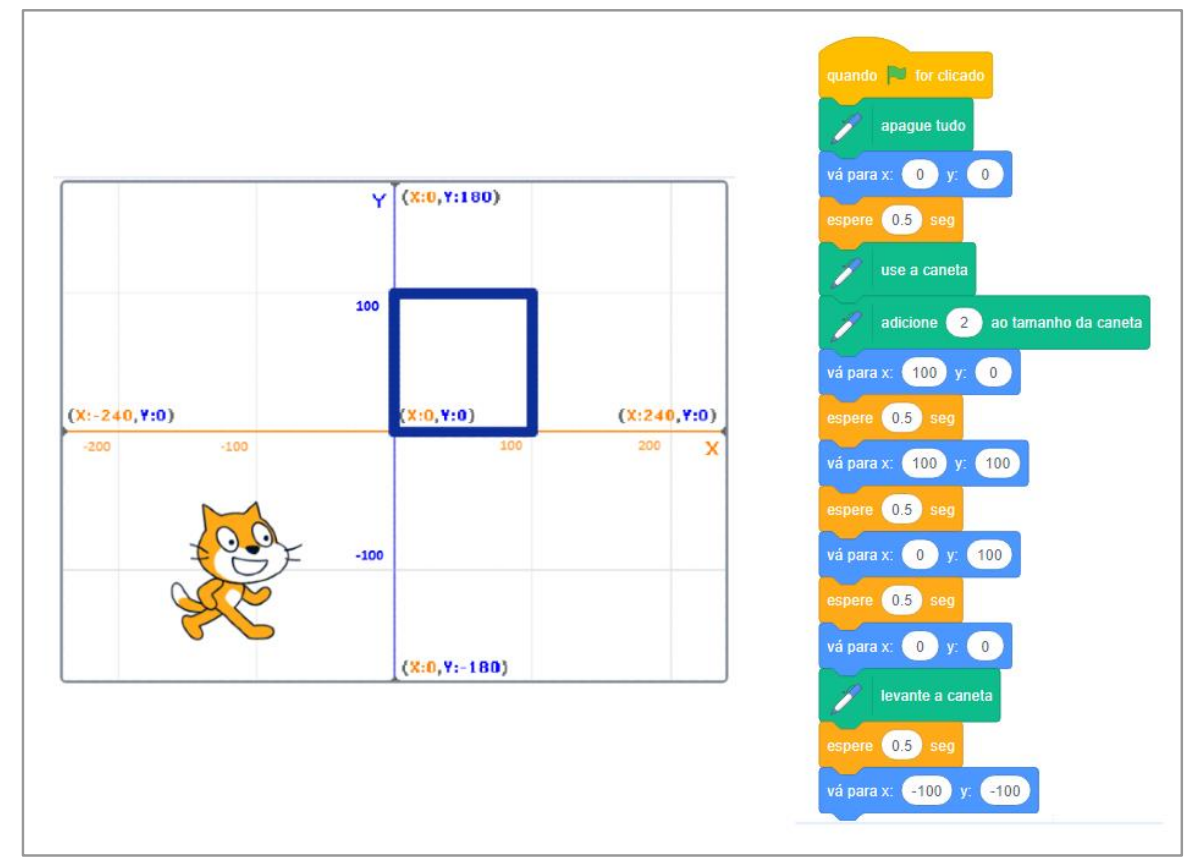

Fonte: Elaborada pelos autores (2018)

Solicitamos que os alunos criassem uma animação utilizando o minirroteiro proposto, mas que escolhessem seus personagens conforme a sua criatividade. Após executada a tarefa pedimos que associassem outros blocos em busca da descoberta de novas funcionalidades, mas sempre procurando correlacioná-las com a abordagem de conceitos matemáticos de numeração na reta numérica, números positivos, negativos, ponto de referência, pares ordenados e plano cartesiano.

\section{Reflexões sobre a Prática Pedagógica}

Quanto ao comportamento dos alunos, percebemos que houve mudança de postura significativa em relação ao anterior, fruto da intervenção enérgica do professor de Matemática. Notamos também que o fato da inclusão do minirroteiro na condução dos experimentos potencializaram o tempo e permitiram que os alunos pudessem fazer no script diversas modificações e testes, possibilitando ainda que pudessem retornar ao script original quando suas modificações não lhes agradavam. Neste encontro, todos conseguiram terminar as tarefas e todos os programas desenhavam um quadrado na tela do palco. Os alunos 
começaram a modificar as cores e a espessura dos traços, assim como desenhar outras formas geométricas, retas ou mudanças de trajetória pelo plano cartesiano.

\section{$\underline{\text { Apontamentos Didáticos }}$}

Os comandos utilizados na aula anterior não foram revisados nesta aula (nem nas seguintes) com o objetivo de avaliar se houve aprendizagem sobre o seu uso. Assim, foi possível perceber que todos já estavam fazendo uso dos blocos lógicos sem receio, exceto sobre algumas configurações específicas, o que reforça que houve o aprendizado através das experiências vivenciadas. Percebemos também que a animação e a empolgação dos alunos continuavam em alta, desde os corredores da escola até o interior da sala de informática. Este fato fez com que alunos de outras turmas procurassem a direção da escola com o intuito de conseguir uma vaga na formação. Próximo ao final do encontro, arguimos informalmente para alguns grupos sobre quais procedimentos seriam necessários para determinar um retângulo e de posse do minirroteiro impresso explicaram com segurança todas as modificações necessárias para executar a nova sugestão. Basicamente todos os fatos revelados qualitativamente no encontro anterior se repetiram, e no quesito criatividade, atenção concentrada e compartilhamento de descobertas os alunos se superaram, o que demonstra que a aprendizagem matemática pode ser motivadora, quando ministrada em parceria com as tecnologias digitais.

\section{Terceiro Encontro: Operações de soma e subtração de números inteiros usando o Scratch}

No terceiro encontro, logo após findado os ritos da apresentação, foram entregues os roteiros contendo os scripts da tarefa do dia. O foco foi estudar os conceitos sobre variáveis numéricas, operadores e jogo de sinais que deveriam ser utilizados para produzir um algoritmo que solicite ao usuário a inserção de dois valores positivos ou negativos através do teclado (Figura 5), o programa deve receber esses valores, efetuar a operação e deslocar o objeto (sprite) para o local do resultado situado sobre a reta numérica. O objetivo desta tarefa volta-se para desenvolver uma rotina de programação que explore conceitos sobre operações com números de sinais diferentes e a sua localização na reta numérica, com vistas a estimular o cálculo mental, o raciocínio lógico e fornecer uma oportunidade de aplicar na prática essas operações básicas que são indispensáveis para atividades do cotidiano. 
Figura 5:Algoritmo que executa a operação matemática e a tela do jogo com a operação de soma e subtração na reta numérica

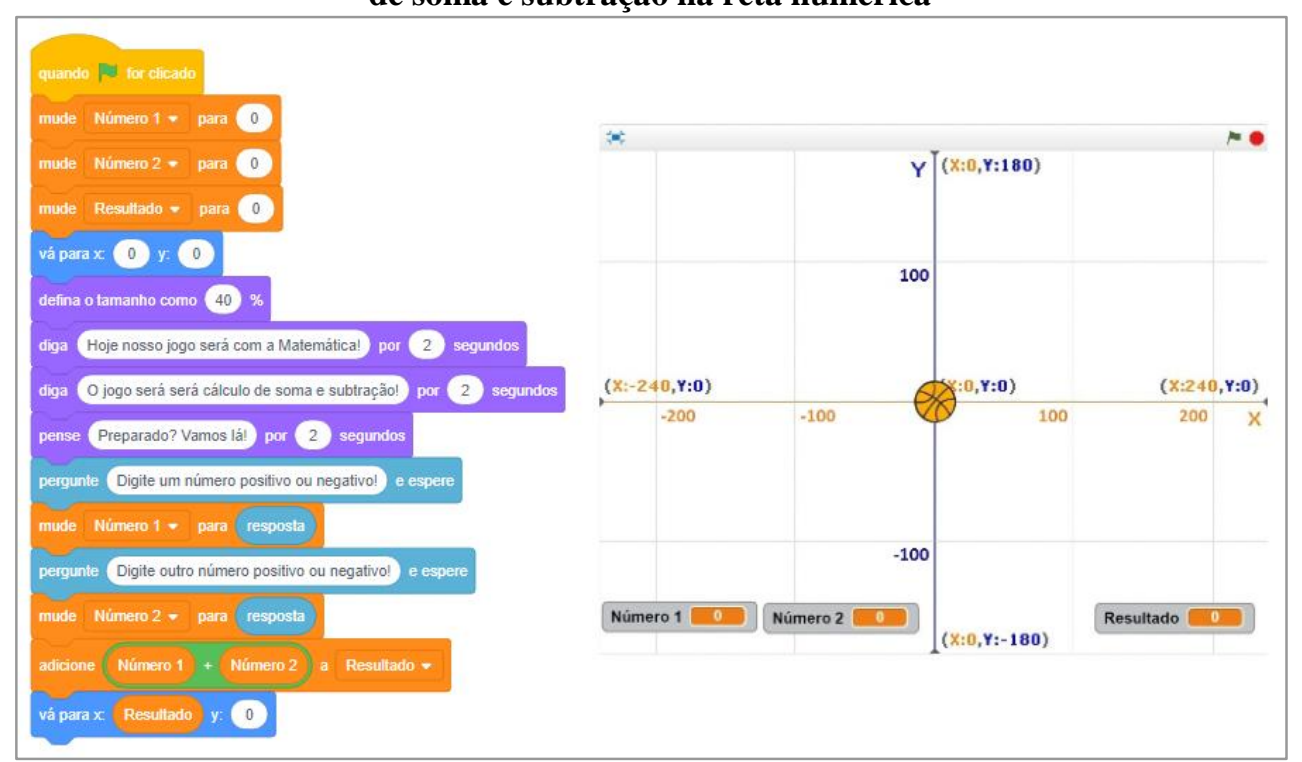

Fonte: Elaborada pelos autores (2018)

Nesta tarefa, os alunos foram estimulados a alterar no algoritmo somente o bloco "soma" por outros blocos de operações (Figura 6) e analisar se os novos resultados eram condizentes com os cálculos realizados à mão.

Figura 6: Blocos lógicos dos operadores

\begin{tabular}{|l|l|}
\hline \multicolumn{2}{|l|}{ OPERADORES } \\
\hline $0+0$ & Soma os dois números \\
\hline $0 \cdot 0$ & Subtrai o segundo número do primeiro \\
\hline $0 \cdot 0$ & Multiplica os dois números \\
\hline 000 & Divide o primeiro número pelo segundo \\
\hline
\end{tabular}

Fonte: Elaborada pelos autores (2018)

\section{Reflexões sobre a Prática Pedagógica}

Nesta tarefa, tivemos alguns problemas de incompatibilidade entre alguns blocos lógicos do Scratch versão 1.4 que compõe o pacote de programas que acompanha o sistema operacional Linux Educacional. O script proposto não executava a rotina da mesma forma em todos os computadores em razão de alguns estarem desatualizados, as variáveis não armazenavam os valores e consequentemente não apresentava o resultado. Isso fez com que alguns grupos não obtivessem êxito em sua atividade, o que gerou certo descontentamento. Contudo, foi esclarecido que o problema era decorrente da desatualização de alguns computadores, mas que traria soluções para o problema em nosso próximo encontro. Nesta 
aula não estiveram presentes os professores de matemática e informática por motivos desconhecidos.

\section{$\underline{\text { Apontamentos Didáticos }}$}

Nesta atividade, percebemos que houve dificuldade na criação das variáveis, pois os alunos ainda não tinham estudado o tema em outras séries. Assim, tivemos que complementar o roteiro impresso com a criação e configuração deste bloco lógico e os discentes passaram a acompanhar via projetor esse trecho do script. Superado este entrave, demos andamento nas atividades. Durante a apresentação fizemos uma breve exposição dialogada com objetivo de avaliar como estavam os seus conhecimentos em relação à operação matemática entre números com sinais opostos. Verificamos que a maioria já conhecia as operações, mas não sabiam claramente como fazê-las, assim visualizamos um alvo a ser atingido através de um jogo matemático desenvolvido. Observamos que havia certa ansiedade em executar as tarefas, o que é algo positivo, mas tivemos que acalmá-los, centrá-los no objetivo que era o de estudar números inteiros e que o jogo era apenas o caminho a nos guiar, apesar de considerá-la emergente diante do avanço do aprendizado.

\section{Quarto Encontro: Operações de soma, subtração, divisão e multiplicação de números inteiros usando o Scratch}

No quarto encontro, os objetivos estavam voltados para sanar os problemas do encontro anterior e inserir novas funcionalidades no programa já desenvolvido. Entre as novidades estavam a inclusão dos algoritmos de multiplicação e divisão, além do algoritmo de pontuação para armazenar os méritos recebidos sempre que o jogador acertar o resultado da operação, como mostra a Figura 7, acerca da tela do jogo reconstruído.

Para sanar o problema da incompatibilidade entre alguns blocos, parte do código do programa anterior teve que ser reescrito, o que mais uma vez gerou frustração nas equipes, porém explicamos que o problema encontrado não daria para ser contornado de outra forma, mas que havíamos acabado de receber uma oportunidade de sucesso e que deveríamos aproveitá-la. 
Figura 7: O Jogo da Matemática

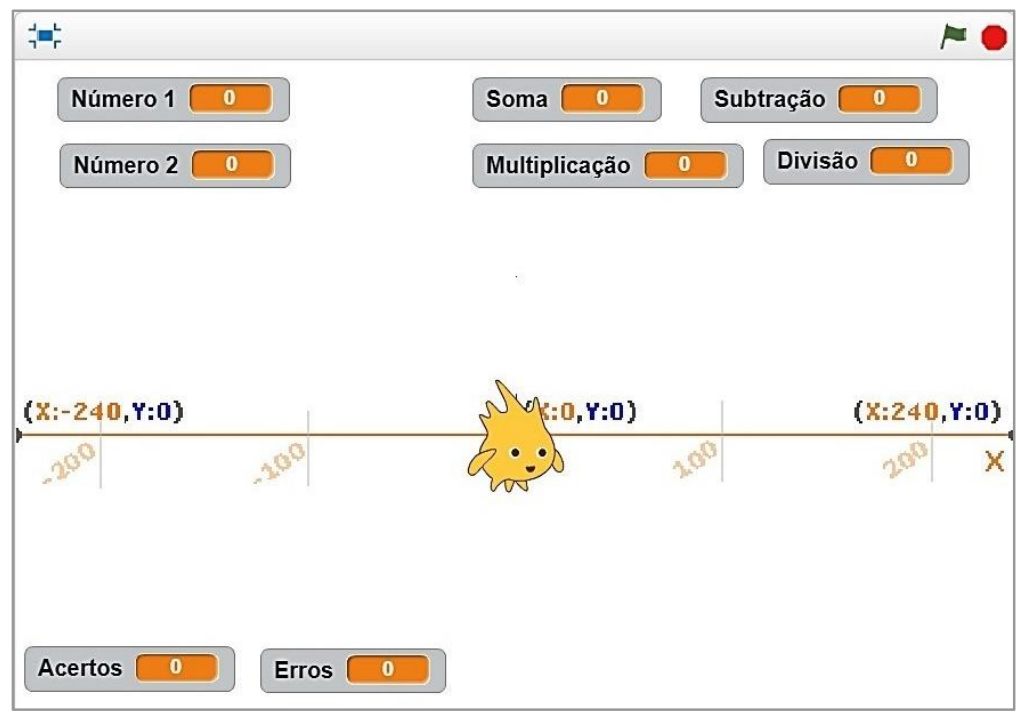

Fonte: Elaborada pelos autores (2018)

Essa atividade foi considerada por nós como a mais complexa, pois os alunos necessitavam entender como as operações matemáticas acontecem para poder encaixar os blocos e também sobre as variáveis, além dos blocos de decisão. Para esclarecer algumas dúvidas, foi dada uma breve exposição dialogada em que se abordava a presença da tomada de decisão no nosso dia-a-dia, assim como correlacionar os conceitos de variáveis com bolsas, mochilas, carteiras e cofres. Essa estratégia ajudou os alunos a entender melhor o que lhes estavam sendo apresentados para a sua aprendizagem.

Para dar apoio na condução das atividades, entregamos impressas as duas primeiras partes do script a serem desenvolvidas, como mostrado na Figura 8, ficando a cargo das equipes a ação para desenvolver os outros dois. 
Figura 8: Blocos de script fornecidos

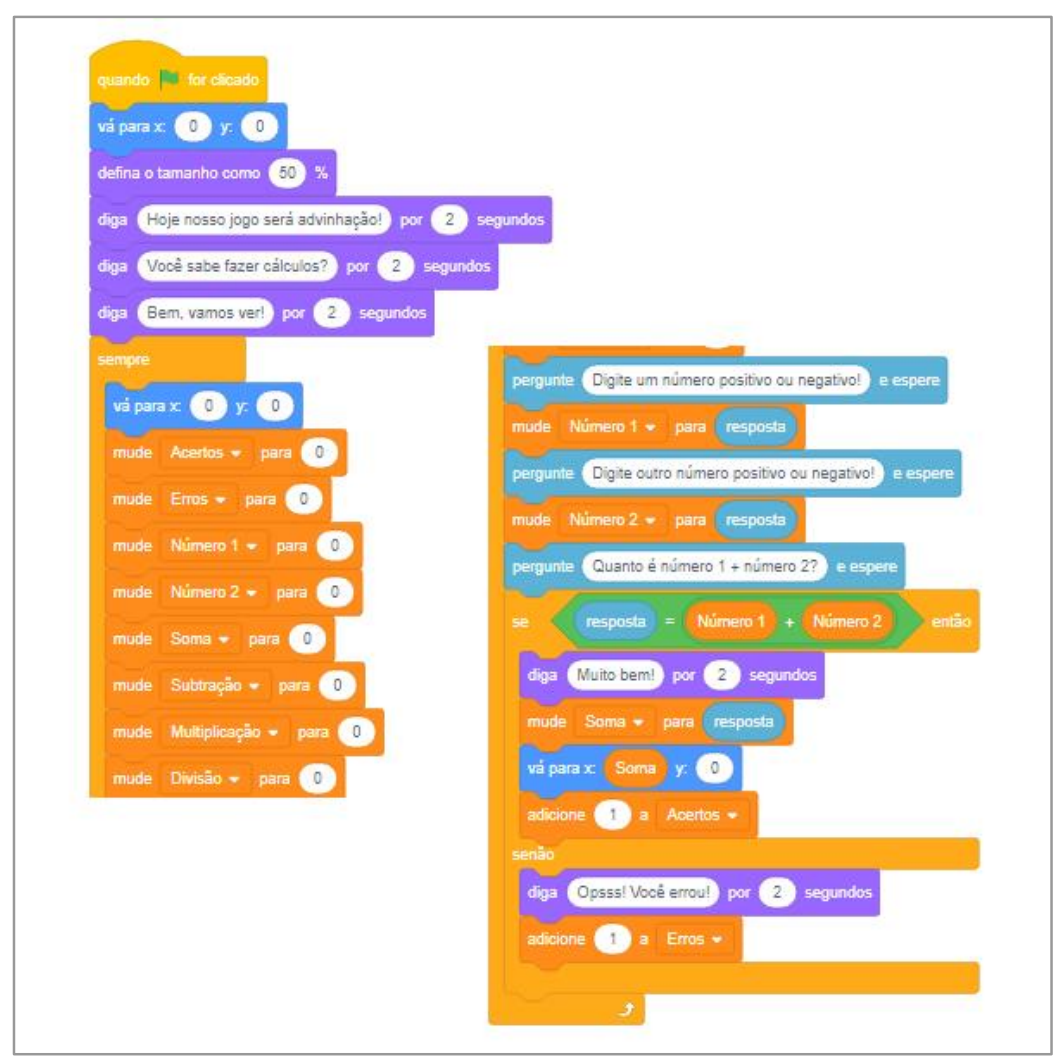

Fonte: Elaborada pelos autores (2018)

\section{Reflexões sobre a Prática Pedagógica}

Pela complexidade embutida nesta tarefa, percebemos que os alunos tiveram dificuldades em comprender o funcionamento do bloco lógico de decisão. Dessa forma, desenvolvemos um script mais simples, por ser da realidade do seu cotidiano escolar, como mostrado na Figura 9, exibimos na lousa, com o auxílio do projetor, o que foi suficiente para sanar as dúvidas restantes. Scripts desenvolvidos pelos alunos completam o programa chamado "O Jogo da Matemática".

Figura 9: Blocos de decisão e sua simplificação

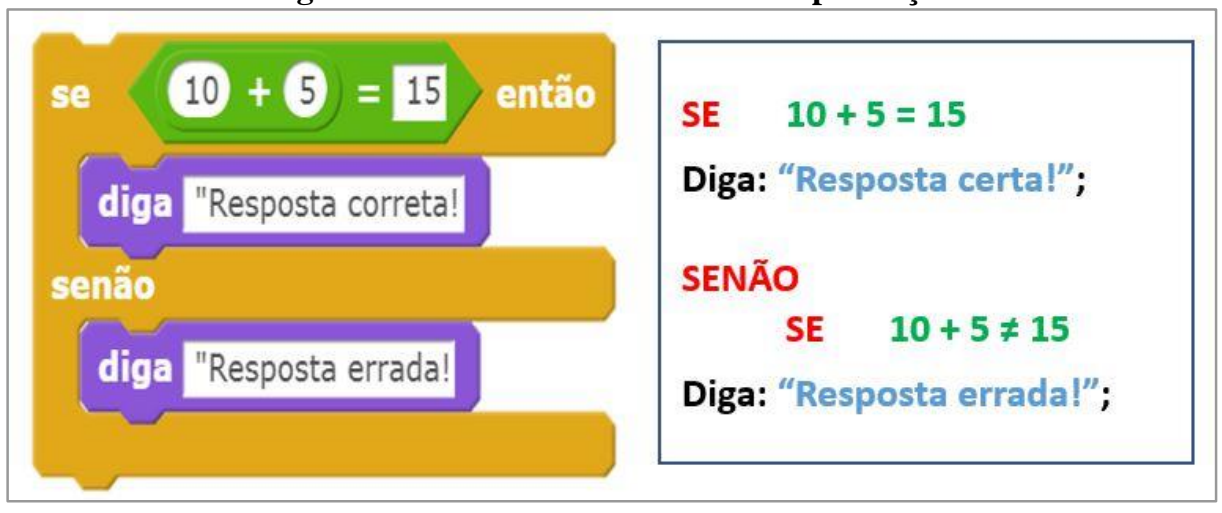

Fonte: Elaborada pelos autores (2018) 


\section{$\underline{\text { Apontamentos Didáticos }}$}

Neste encontro, foi necessário revisar alguns dos blocos lógicos já conhecidos. Esta decisão se justifica pelo fato de haver uma complexidade de abstração do jogo e pela necessidade de se compreender como as variáveis conseguem guardar as informações e transmiti-las quando requeridas. Parte desta dificuldade é decorrente da falta de conhecimento prévio sobre variáveis numéricas, uma vez que o professor da disciplina ainda não as abordou. Daí, extraímos uma importante informação: a de que os conceitos matemáticos devem ser previamente discutidos e exercitados em sala de aula e só depois tentar fixá-los com o auxílio das tecnologias digitais. Apesar das dificuldades visualizadas, a maioria das equipes conseguiu criar toda a rotina de programação, contudo não foi possível fazer uma atividade dinâmica através de competições entre as equipes, conforme planejado, em virtude do término do horário da aula, mas ficou salvo nos computadores e sob a responsabilidade do professor da disciplina explorá-la no tempo devido. Atendendo a pedidos, aos que não conseguiram concluir a atividade, foi dada uma nova oportunidade pelo seu professor, conforme acordo firmado.

\section{Quinto Encontro: Desenvolvimento de um robô virtual: O ROBOCAT - O gato seguidor de linha}

Neste último encontro, foi desenvolvido o tão esperado robô virtual. Na apresentação inicial foram abordados elementos sobre a construção de robôs e sobre a sua aplicação nos dias atuais. Descrevemos também sobre os blocos lógicos responsáveis pela tomada de decisão para seguir em frente, virar à direita ou à esquerda, explanando a importância dos ângulos e dos sensores responsáveis por "enxergar" para onde vamos e para que lado devemos virar para não colidir.

Logo após as considerações iniciais, foram entregues os minirroteiros com os comandos básicos a serem executados, mas que após a execução os scripts deveriam ser alterados em busca da personalização, como mostramos na Figura 10. A pista onde o robô deverá trilhar ficou a cargo de cada equipe, pois apesar de os scripts serem iguais, o comportamento do robô variava de acordo com os tipos de curvas, ângulos existentes ou cores de fundo da pista.

Esta atividade tem caráter interdisciplinar, pois os alunos necessitam de outros conhecimentos ou pontos de vistas não ensinados na intervenção pedagógica aqui 
desenvolvida para tentar contornar os problemas que aparecerão em cada tipo de curva criada para a pista. Este fato conduz o professor a ser dinâmico e buscar outros recursos que possam facilitar a aprendizagem em outras vias.

Figura 10: Robô virtual e o script completo do ROBOCAT

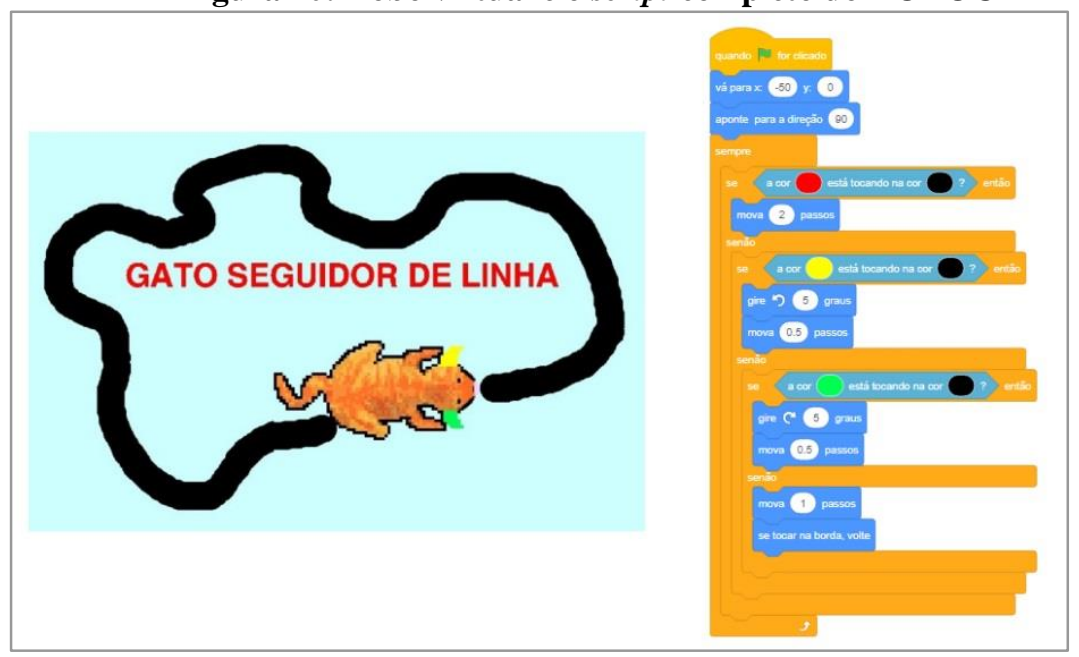

Fonte: Elaborada pelos autores (2018)

O foco principal desta atividade volta-se para a inserção de conceitos sobre ângulos e sobre as prioridades que algumas tarefas têm em relação a outras, explorados a partir do ponto de vista de mudanças de trajetórias, assim como tentar desenvolver suas habilidades em relação à tomada de decisão e à resolução de problemas, buscando correlacioná-las com as diversas situações do cotidiano.

\section{Reflexões sobre a Prática Pedagógica}

Apesar de o script fornecido ser pequeno, ele condensa muitas informações e instruções a serem executadas pelos mais simples equipamentos eletromecânicos. Esse fato exigiu dos alunos um nível de abstração e entendimento ainda não desenvolvidos, pois tais decisões são tomadas por nós, de maneira automática e sem perceber. Contudo, apesar das dificuldades, notamos engajamento entre as equipes e o sentimento foi de satisfação, pois conforme terminavam suas tarefas, levantavam-se das cadeiras e iam chamar outros colegas para ver o funcionamento de seu robô, característico do processo interativo do construcionismo.

\section{$\underline{\text { Apontamentos Didáticos }}$}

Este encontro foi o que mais necessitou do auxílio do professor na mediação da aprendizagem, devido ao fato de as personalizações das pistas necessitarem receber 
calibração de forma independente. No entanto, logo após entenderem a forma de orientação utilizada pelo robô virtual, as equipes começaram a personalizar também as cores dos sensores de seus personagens, o que demonstra certa necessidade de diferenciação vividas pelos nossos estudantes em relação aos colegas, assim como seu elevado nível de criatividade.

\section{Considerações finais}

A presente pesquisa apresenta os resultados obtidos através da aplicação prática de um projeto de intervenção pedagógica, utilizando a linguagem programação no Scratch como uma ferramenta didática de apoio ao processo de ensino e aprendizagem de Matemática, para o Ensino Fundamental, atrelada ao uso pedagógico de tecnologias digitais. Com base nos dados coletados e nas observações realizadas, registradas no diário de docência do professor-pesquisador, apontamos que as tecnologias digitais em sala de aula possuem potencial para contribuir ao exercício da prática docente em diversas áreas do conhecimento, tal como aqui expressado no ensino de operações matemáticas.

Com base na literatura da área, destacamos que parte do insucesso vivenciado pelos alunos em matemática está relacionado à forma tradicional com que ela é ministrada, com poucas conexões com a realidade prática dos alunos, ainda pautada em uma racionalidade técnica. Diante deste cenário e aproveitando o fascínio que os jovens tem por tecnologias digitais, jogos e informática, desenvolvemos esta intervenção pedagógica usando a linguagem de programação no Scratch, o que nos permitiu explorar conceitos matemáticos sobre operações com números inteiros, o que pode ser caracterizado nesta pesquisa, de forma construcionista, vislumbrando as competências e as habilidades necessárias para a aprendizagem.

Acerca do uso das tecnologias digitais em sala de aula e com base nas duas dimensões formativas que emergiram da análise dos dados, destacamos a importância do papel da mediação pedagógica do professor de matemática frente ao conhecimento latente dos estudantes e aquele que estar por vir. De um lado, as reflexões sobre a prática pedagógica do professor, aqui também atuando como pesquisador, possibilitou desenvolver competências importantes para o seu exercício, ampliando a postura pedagógica e de reflexão crítica sobre a necessidade do planejamento didático ao se trabalhar com estas tecnologias. Por outro lado, os apontamentos didáticos identificaram perspectivas de se criar espaços de discussão do trabalho em equipe entre os alunos, apontaram dificuldades técnicas 
e até mesmo didáticas da mediação com uso de tecnologias digitais em sala em função de variáveis destacadas ao longo do texto, gerando momentos de reflexão sobre a docência, da aprendizagem matemática, além da importância de que ser professor exige que o processo de ensinar e aprender contenha habilidades a serem desenvolvidas no contexto educacional.

Nesse sentido e, alinhado ao uso de tecnologias digitais, a linguagem de programação no Scratch apresentou-se como uma ferramenta intuitiva no uso de scripts embutidos e blocos que encaixavam uns nos outros, o que possibilitou que as crianças sem o conhecimento em programação pudessem desenvolver seus projetos "simplesmente brincando", de forma lúdica e usando tecnologias digitais para a aprendizagem matemática. Esta ação possibilitou aos alunos desenvolver a sua criatividade, o raciocínio lógico, a abstração e a habilidade na resolução de problemas matemáticos (e do cotidiano). Essas características tornaram-nas ideais para o desenvolvimento prático da intervenção ora realizada, em termos pedagógicos e metodológicos.

Durante a realização dos cinco encontros, percebemos que os alunos sempre chegavam animados e ficavam atentos para a apresentação da tarefa a ser executada. Logo após entendidos os objetivos e de posse dos minirroteiros que desenvolvemos, iniciavam as atividades que, em geral, eram sempre cumpridas. Tais ações possibilitaram analisar os elementos da prática pedagógica desenvolvida na intervenção, com vistas a uma aprendizagem matemática construcionista por meio do uso de tecnologias digitais, o que nos aporta segurança quanto ao cumprimento dos objetivos desta pesquisa. Os minirroteiros e as habilidades matemáticas desenvolvidos foram repassados aos professores de Matemática e Informática para servirem de base para sua utilização com outras turmas e futuramente serem compartilhados no site do Scratch.

É importante ressaltar que no processo de programação de computadores existe muita Matemática embutida e que esta não se apresenta do mesmo jeito que é ensinado nas escolas. Assim, apontamos (e apostamos) que a abordagem de operações matemáticas através da programação contribui positivamente para o desenvolvimento do raciocínio lógico, da criatividade, da habilidade em trabalhar em equipes em sala de aula, em uma abordagem construcionista. Tais qualidades são úteis no estudo de outros conteúdos e o principal, desperta nos alunos um olhar diferente para a aprendizagem matemática em relação aos conhecimentos que já trazem consigo, ampliando os seus olhares de mundo e (trans)formando as suas práticas sociais. 


\section{Referências}

Almeida, C. M. de, Scheunemann, C. M., Santos, M. J. dos \& Lopes, P. T. C. (2019). Propuestas de metodologías activas utilizando tecnologías digitales y herramientas metacognitivas para auxiliar en el proceso de enseñanza y aprendizaje. Revista Paradigma, XL(Número Extra 204-220. https://doi.org/10.37618/PARADIGMA.10112251.2019.p204\%20\%E2\%80\%93\% 20220.id748

Baião, E. R. (2016). Desenvolvimento de uma metodologia para o uso do scratch for arduino no ensino médio. [Dissertação de Mestrado, Universidade Estadual de Campinas, Campinas - SP]. Repositório da UNICAMP. Recuperado de http://repositorio.unicamp.br/jspui/bitstream/REPOSIP/305320/1/Baiao_Emerson Rodrigo_M.pdf.

Bicudo, M. A. V.; Borba, M. de C. (2005). Educação Matemática: Pesquisa em Movimento. $2^{\mathrm{a}}$ ed. Cortez.

Bogdan, R. C. \& Biklen, S. K. (1994). Investigacão qualitativa em educação. (M. J. Alvarez, S. B. dos Santos \& T. M. Baptista, Trad.). Porto Editora, LDA.

Brasil. (2015). SAEB - Sistema de Avaliação da Educação Básica. Acesso em: 05 mar. 2018. http://download.inep.gov.br/educacao_basica/saeb/aneb_anresc/resultados/resumo _dos_resultados_saeb_2015.pdf.

Cabral, Ronaldo Vieira. (2015). O ensino de matemática e a informática: uso do scratch como ferramenta para o ensino e aprendizagem da geometria. [Dissertação de Mestrado, FACNORTE - Faculdade do Norte do Paraná]. FACNORTE. http://www.acervo.paulofreire.org:8080/jspui/bitstream/7891/3626/1/FPF_PTPF_ 07 0077.pdf.

Carneiro, R. F. \& Passos, C. L. B. (2014). A utilização das tecnologias da informação e comunicação nas aulas de matemática: limites e possibilidades. Revista Eletrônica de Educação, 8(2), 101-119. http://dx.doi.org/10.14244/19827199729.

Castro, A. \& Koscianski, A. (2017). O uso da programação scratch para o desenvolvimento de habilidades em crianças do ensino fundamental. Revista Tecnologias na Educação, 9(19), 1-12.

Fiorentini, D. (2008). A pesquisa e as práticas de formação de professores de matemática em face das políticas públicas no Brasil. Boletim de Educação Matemática, 21(29), 4370 .

Freire, P. (1996). Pedagogia da autonomia. Paz e Terra.

Hernandez, Ronald M. (2017). Impacto de las TIC en la educación: Retos y Perspectivas. $\begin{array}{llll}\text { Propósitos } & y & \text { Representaciones, } & \text { 3(1), }\end{array}$ http://dx.doi.org/10.20511/pyr2017.v5n1.149.

Jenkins, H., Clinton, K., Purushotma, R., Robison, Alice J. \& Weigel, M. (2009). Confronting the challenges of participatory culture: media education for the $21 \mathrm{st}$ century. The MacArthur Foundation.

Kamii, C. (1995). Desvendando a aritmética: implicações na teoria de Piaget. Papirus.

Minayo, M. C. de S. (2012). Pesquisa Social: teoria, método e criatividade. Vozes. 
Nóvoa, A. (1992). Formação de professores e profissão docente. Em A. Nóvoa (Ed.). Os professores e sua formação (pp. 139-158). Lisboa: Instituto de Inovação Educacional.

Papert, S. (1994). A máquina das crianças: repensando a escola na era da informática. Tradução de Sandra Costa. 1.ed . Artes Médicas.

Rivera-Vargas, P. \& Lindín C. (Ed.) (2018). Tecnologías digitales para transformar la sociedad. Albacete: LiberLibro.

Rodrigues-Moura, S. (2016). Avaliação em aulas de ciências e matemáticas: narrativa (auto)biográfica como instrumento de formação do professor-pesquisador. Boletim Online de Educação Matemática, 4(6), 28-47.

Sampaio, M. N. \& Leite, L. S. (1999). Alfabetização tecnológica do professor. Vozes.

Sanches, J. G. (2004). Dificuldades de aprendizagem e intervenção psicopedagógica. Artmed.

Santos, C. F. R. (2017, 21 a 23 de setembro). Algumas possibilidades do aplicativo scratch e da robótica educacional no ensino de matemática. [Palestra] Encontro Paranaense de Educação Matemática, Paraná, Brasil. http://www.sbemparana.com.br/eventos/index.php/EPREM/XIV_EPREM/paper/v iewFile/27/3.

Santos, A. F. P. (2012). Uso de tecnologias digitais em atividades do ensino fundamental: uma experiência com alunos da rede municipal de Vesparsiano. EDUFU.

Sápiras, F. S., Vecchia, R. D. \& Maltempi, M. D. (2015). Utilização do Scratch em sala de aula. Educação Matemática Pesquisa, 17(5), 973-988.

Scratch: imagine, program, share. (2018). Acesso 05 marzo de 2018. https://scratch.mit.edu/.

Soares, C. V. C. de O. (2005). As intervenções pedagógicas do professor em ambientes informatizados: uma realidade a ser construída. [Dissertação de Mestrado, Universidade Federal do Rio Grande do Sul]. UFRGS. https://www.lume.ufrgs.br/bitstream/handle/10183/7141/000539705.pdf?sequence $=$.

Zilli, S. do R. (2004). A robótica educacional no ensino fundamental: perspectivas e prática. [Dissertação de Mestrado, Universidade Federal de Santa Catarina]. UFSC. https://repositorio.ufsc.br/xmlui/handle/123456789/86930

Autores

Marcelo Miranda Damasceno

Especialista em Docência para a Educação, Profissional, Científica e Tecnológica (IFPA) e bacharel em Engenharia de Controle e Automação (ESTÁCIO). Atualmente é servidor público federal no Instituto Federal de Educação, Ciência e Tecnologia do Pará (IFPA/Campus Parauapebas). Tem experiência na área de automação residencial, eletrônica embarcada, sistemas de controle industrial e docência para a Educação Profissional. E-mail: marcelo.damasceno@ifpa.edu.br. 
Sebastião Rodrigues-Moura

Doutorando em Educação em Ciências e Matemática (REAMEC/UFMT). Professor do Instituto Federal de Educação, Ciência e Tecnologia do Pará. Atua na área de docência em

Física e Formação de Professores. Tem experiência em educação em ciências, fundamentos e metodologias para o ensino de ciências, pesquisa narrativa e formação de professores.. E-mail: sebastiao.moura@ifpa.edu.br. 